\title{
CULTURA DIGITAL, CAPITAL CULTURAL E CAPITAL TECNOLÓGICO: UMA ANÁLISE DAS PRÁTICAS PEDAGÓGICAS NO ENSINO SUPERIOR
}

\author{
DIGITAL CULTURE, CULTURAL CAPITAL, AND TECHNOLOGICAL CAPITAL: AN \\ ANALYSIS OF PEDAGOGICAL PRACTICES IN HIGHER EDUCATION
}

\author{
Daiani Damm Tonetto Riedner \\ Doutora em Educação \\ Universidade Federal de Mato Grosso do Sul - UFMS. \\ Campo Grande, MS - Brasil. \\ daiani.riedner@ufms.br \\ Magda Pischetola \\ Doutora em Educação \\ IT University of Copenhagen - ITU. \\ Copenhagen, Dinamarca. \\ magd@itu.dk
}

\begin{abstract}
Resumo: Este artigo analisa e discute a construção teórica do conceito de capital tecnológico, fundamentado no conceito de capital cultural, com base em uma pesquisa sobre o uso de tecnologias digitais nas práticas pedagógicas de cursos de formação inicial de professores. A problemática da pesquisa teve como foco conhecer as características das práticas pedagógicas dos professores e identificar algumas práticas que possam ser definidas inovadoras a partir das ações pedagógicas que professores e alunos considerem como tal. O trabalho apresenta o percurso teórico e metodológico que nos permitiu fazer a relação da cultura digital, do capital cultural e do capital tecnológico a partir das análises das práticas pedagógicas dos professores. O design metodológico da pesquisa contemplou revisão de bibliografia, análise dos projetos de curso, questionários e entrevistas. A base empírica do estudo foi construída por meio dos dados de 220 respondentes de um questionário online e de 45 entrevistas semiestruturadas desenvolvidas com estudantes e professores dos cursos de licenciatura de uma Instituição Pública de Ensino Superior. Com bases nos dados dos questionários, foram constituídos os índices de uso social e pedagógico de tecnologias digitais, que por sua vez, resultaram no índice de capital tecnológico dos professores. A pesquisa permite conceituar teórica e empiricamente o capital tecnológico e define os desafios principais para a integração de tecnologias digitais nas práticas pedagógicas dos professores de ensino superior, com vistas à construção de práticas inovadoras.
\end{abstract}

Palavras-chave: cultura digital; capital cultura; capital tecnológico; formação de professores; tecnologias digitais.

\begin{abstract}
This paper analyzes and discusses the theoretical construction of the concept of technological capital, grounded on the concept of cultural capital, based on research on the use of digital technologies in the pedagogical practices within initial teacher training courses. The research problem focused on identifying the characteristics of professors' pedagogical practices and identifying some innovative practices defined by which pedagogical actions professors and students consider innovative. The paper presents the theoretical and methodological path that allowed us to relate digital culture, cultural capital, and technological capital based on the analysis of professors' pedagogical practices. The methodological design comprises bibliographic review, course project analysis, online survey, and interviews. We built the empirical basis of the study on the data of 220 respondents to the online survey and 45 semistructured interviews developed with students and professors of undergraduate courses of a Public Higher Education Institution. Based on the data from the surveys, we constituted indices of social and pedagogical use of digital technologies, which in turn resulted in the professors' technological capital index. The research allows the theoretical and empirical conceptualization of technological capital, and defines the main challenges for the integration of digital technologies in the pedagogical practices of higher education professors, meaning to develop innovative practices.
\end{abstract}

Keywords: digital culture; cultural capital; technological capital; teacher training; digital technologies.

Para citar - (ABNT NBR 6023:2018)

RIEDNER, Daiani Damm Tonetto; PISCHETOLA, Magda. Cultura digital, capital cultural e capital tecnológico: uma análise das práticas pedagógicas no ensino superior. Eccos - Revista Científica, São Paulo, n. 57, p. 1-20, e15907, abr./jun. 2021. Disponível em: https://doi.org/10.5585/eccos.n57.15907. 


\section{Introdução}

As tecnologias digitais, principalmente a internet, têm influenciado e transformado, cada vez mais, as relações sociais e educacionais. No ensino superior, os cursos de formação de professores têm passado por diversas reformulações curriculares e nas práticas pedagógicas, no sentido de contemplar as discussões relacionadas ao uso das tecnologias digitais.

A literatura das últimas décadas destaca que a inovação da prática pedagógica tem como centro de atenção as ações dos professores e as suas práticas, que têm sua origem nos processos de formação inicial. Nesse sentido, analisar a prática dos professores do ensino superior no que diz respeito ao uso de tecnologias e as possibilidades que essas tecnologias têm de potencializar as práticas inovadoras, se apresenta como um importante objeto de estudo no campo da educação.

Este artigo apresenta o recorte de uma pesquisa que teve como objetivo analisar as caraterísticas das práticas pedagógicas com uso de tecnologias digitais em uma Instituição Pública de Ensino Superior ${ }^{1}$. Ainda pouco explorado teórica e empiricamente, o conceito de capital tecnológico foi utilizado para compreensão dos aspectos que fundamentam as práticas pedagógicas com uso de tecnologias digitais no âmbito dos cursos de formação de professores. Para sustentar essa proposta, a metodologia de pesquisa utilizou-se de três instrumentos: (1) análise documental dos projetos pedagógicos de curso; (2) questionários para estudantes e professores; (3) entrevistas semiestruturadas com estudantes e professores.

O conceito de capital tecnológico foi investigado principalmente pelos dados quantitativos de um questionário online composto por 50 questões para professores, 46 questões para estudantes e que ficou accessível por nove meses. Para os fins desse trabalho, apresentamos os dados relativos às 59 respostas coletadas dos professores ${ }^{2}$. A partir desses dados, no SPSS foram criados indicadores de uso social e uso pedagógico de tecnologias digitais pelos estudantes e professores, por meio da análise fatorial.

Em casos nos quais se tem um número grande de variáveis medidas e correlacionadas entre si, é possível, a partir da análise fatorial, identificar um número menor de novas variáveis alternativas, não correlacionadas e que de algum modo sumarizem as informações principais das variáveis originais. Essas novas variáveis são chamadas de fatores ou variáveis latentes (MINGOTI, 2007).

\footnotetext{
A pesquisa teve o apoio da Fundação de Apoio ao Desenvolvimento do Ensino, Ciência e Tecnologia do Estado de Mato Grosso do Sul - Fundect.

${ }^{2} \mathrm{O}$ questionário teve 300 entradas de respostas, das quais 220 foram utilizadas na análise, por terem sido respondidas de forma completa. Dessas 220 respostas, 161 foram de estudantes dos cursos de licenciatura que estavam cursando o último ou penúltimo período do curso e 59 respostas dos professores dos mesmos cursos. A plataforma utilizada para a coleta de dados foi a LimeSurvey e o software para análise dos dados foi o SPSS.
} 
De forma sintética, a análise fatorial consistiu em agrupar questões que tinham fatores semelhantes, por exemplo: duas ou mais questões que indicavam a frequência de uso de tecnologias na prática pedagógica. Com esses fatores (questões) agrupadas, a análise fatorial deu origem a uma nova variável que sintetizou as três anteriores. Foram realizadas análises fatoriais para criação dos índices de: (i) uso social de tecnologias; (ii) uso de tecnologias na prática pedagógica; e (iii) capital tecnológico dos professores.

Para discutir e conectar essas variáveis com o conceito de cultura digital, o texto está organizado em três seções. A primeira apresenta uma introdução à conceituação de cultura digital e sua importância no contexto dos cursos de formação inicial de professores. A segunda seção aborda a análise da inter-relação dos conceitos de capital cultural e capital tecnológico. A terceira e última seção apresenta os dados de pesquisa e algumas considerações advindas do campo empírico.

\section{Cultural digital e formação de professores}

Nós sabemos que a tecnologia não determina a sociedade: é a sociedade. A sociedade é que dá forma à tecnologia de acordo com as necessidades, valores e interesses das pessoas que utilizam as tecnologias (CASTELLS, 2005, p. 17).

O pensamento do sociólogo espanhol Manuel Castells (2005), evidenciado na epígrafe que dá início à esta seção, nos permite compreender a tecnologia como cultura. E é nessa perspectiva que as práticas pedagógicas com uso de tecnologias se apresentam nesse estudo, como práticas culturais, como ação dos professores que são construídas de acordo com suas trajetórias, suas condições reais de existência, seus capitais (cultural, social, escolar, simbólico), considerando o campo específico em que estão inseridos.

Compreender a tecnologia como cultura implica em pensar na cultura digital, que nasceu com a Internet e foi desenhada para ser um espaço universal de comunicação e informação. Nas palavras de Castells (2005), a internet possibilita conectar o global com o local e torna os indivíduos capazes de produzir, com sua atuação e participação em rede, conhecimento e informação.

Para o antropólogo brasileiro Roque Laraia (2008), a cultura é dinâmica. Ela é capaz de direcionar o modo de ver o mundo, os diferentes comportamentos sociais, as posturas corporais e preferências, que são produtos de uma herança cultural. É comum ouvirmos que as crianças "nascem sabendo" manusear dispositivos tecnológicos com muita facilidade. Isso é possível, pois o sistema cultural está em constante mudança, que acompanha o processo de desenvolvimento social, econômico e tecnológico da sociedade. Para Laraia (2008, p. 62), “[...] 
a criança está apta ao nascer a ser socializada em qualquer cultura existente. Esta amplitude de possibilidade, entretanto, será limitada pelo contexto real e específico onde de fato ela crescer".

A cultura possui um conjunto de mecanismos de controle, planos, receitas, regras e instruções que orientam o comportamento das pessoas na sociedade. E na sociedade da informação, cujos sistemas culturais estão permeados pelo uso constante de tecnologias digitais, a cultura digital emerge como uma reinterpretação e reestruturação da cultura ocidental contemporânea, que se potencializa pelas possibilidades de comunicação que são multiplicadas no contexto digital.

Os cursos de formação inicial de professores têm um papel preponderante na formação de profissionais que tenham condições de localizar, selecionar, avaliar e utilizar conteúdos e recursos digitais que sejam capazes de instigar e promover a aprendizagem. Nessa perspectiva, o professor pode ser um agente de transformação da lógica da sua sala de aula na medida em que vai disponibilizar múltiplas oportunidades de participação aos estudantes. "Ele predispõe teias, cria possibilidades de envolvimento, oferece ocasião de engendramentos, de agenciamentos. E estimula a intervenção dos alunos como coautores de suas ações" (SILVA, 2004, p. 9).

A cultura digital aponta para a necessidade de um processo de formação inicial e continuada, que não se limita à instrumentação técnica, mas que considere o currículo como prática cultural e estimule uma busca incessante, a fim de unir a potencialidade das tecnologias com objetivos claros para o desenvolvimento da aprendizagem. O principal desafio que a cultura digital impõe para a educação é a inovação das práticas (em todos os níveis de ensino) com o uso de tecnologias digitais. Essa inovação, que pressupõe apropriação, se dá em um processo de internalização, transformação, participação e colaboração. Na medida em que os professores participam de práticas sociais e pedagógicas com uso de tecnologias digitais, eles modificam as tecnologias e transformam a si mesmos em uma circularidade virtuosa.

\section{Capital cultural e capital tecnológico: inter-relações conceituais}

Para compreender as características das práticas pedagógicas com o uso de tecnologias, consideramos primeiramente necessário pensar nas motivações que levam os professores a usar as tecnologias digitais. Temos como pressuposto que as disposições dos sujeitos, que direcionam suas escolhas e suas práticas, são construídas social e culturalmente. Nesse sentido, como parte que integra o próprio habitus (BOURDIEU, 2004) e como um constructo teóricoconceitual inspirado no conceito de capital cultural de Bourdieu, o capital tecnológico será 
operacionalizado na tentativa de torná-lo observável nas informações produzidas na pesquisa. $\mathrm{Na}$ perspectiva bourdieusiana, o capital cultural pode se apresentar em três estados: incorporado, objetivado e institucionalizado. Apresentamos brevemente a seguir as características de cada um deles.

O capital incorporado se refere à cultura legítima internalizada pelo indivíduo, ou seja, as habilidades linguísticas, postura corporal, crenças, conhecimentos, preferências, hábitos e comportamentos relacionados à cultura dominante. Essa incorporação "[...] pressupõe um trabalho de inculcação e de assimilação, custa tempo que deve ser investido pessoalmente pelo investidor [...]" (BOURDIEU, 2007, p. 74).

Já o estado objetivado define o capital "transmissível em sua materialidade" (BOURDIEU, 2007, p. 77). Refere-se, portanto, à propriedade de objetos culturais valorizados, como por exemplo, livros e obras de arte e tem sua ligação estreita com o capital incorporado, sendo que algumas propriedades se definem apenas em relação com o capital cultural em sua forma incorporada. Por último, o capital institucionalizado é o capital cultural representado pela posse de certificados escolares, que são utilizados socialmente como atestados de certa formação cultural.

Com as devidas proporções conceituais, o capital tecnológico não representa somente a posse dos artefatos tecnológicos, como um estado objetivado, mas vai além do nível material, indicando todo arcabouço de experiências e conhecimentos das diferentes tecnologias que são adquiridas de forma prática (com os usos e como prática social) durante o tempo de socialização. Encontra-se escassa literatura sobre o capital tecnológico e sua definição em relação ao conceito de capital cultural de Bourdieu. Apresentamos a seguir duas pesquisas que trazem contribuições úteis para os fins deste trabalho.

Em estudo de 2004, Freitas utiliza o conceito de "capital tecnológico-informacional" para explicar a relação entre os indivíduos e os artefatos tecnológicos. A autora enfatiza que a compreensão desse conceito deve levar em consideração os aspectos sociais, culturais, educacionais e econômicos dos agentes em um determinado campo. "Quanto mais esse capital estiver presente como parte integrante do habitus de cada indivíduo, mais chances ele terá de obtenção de conhecimento e reconhecimento" (FREITAS, 2004, p. 118). Ainda de acordo com a autora, o conjunto de disposições do capital tecnológico-informacional é constituído por três elementos básicos: 
- Conhecimento técnico específico para o uso de tecnologias digitais;

- Aparato material para colocar em prática tal conhecimento;

- Condições sociais, educacionais e culturais que permitam a aquisição desse saber para o uso das tecnologias digitais.

A investigação realizada no México por Ramírez Martinell, Casillas Alvarado, e Méndez (2014) é o estudo mais recente e teve como foco o uso de tecnologias digitais no ensino superior. Essa pesquisa traz uma proposta conceitual semelhante à de Freitas (2004), mas avança na apresentação de alguns parâmetros para "mensuração"3 do nível de capital tecnológico dos estudantes e professores em contextos educacionais.

$\mathrm{Na}$ definição dos autores, o capital tecnológico compreende o conjunto de saberes e habilidades para uso de tecnologias digitais, que podem diferenciar os indivíduos e lhes dar condições de competir nos diversos campos e espaços sociais. Assim como o capital cultural, o capital tecnológico também pode se apresentar nos três estados: incorporado, objetivado e institucionalizado (RAMÍREZ MARTINELL; CASILLAS ALVARADO; MÉNDEZ, 2014).

O capital tecnológico incorporado indica o grau de domínio das tecnologias, que implica em conhecer e saber utilizar os artefatos tecnológicos em diferentes contextos. No campo educacional, por exemplo, corresponderia ao conhecimento e uso das tecnologias digitais, resultante do tempo de trabalho investido nos processos de aprendizagem (formais ou informais). Ele compreende o processo de socialização básico, onde os saberes que envolvem o uso das tecnologias são preponderantes; o grau de apropriação tecnológica (domínio das tecnologias digitais); o grau de afinidade com as tecnologias digitais; conjunto de saberes e práticas relacionadas aos processos de ensino e aprendizagem.

Já no estado objetivado, o capital tecnológico se apresenta como um conjunto de objetos tecnológicos que são apropriados em sua materialidade, mas que requerem o capital incorporado para sua utilização de forma satisfatória. Da mesma forma que o capital cultural, é necessário um processo de apropriação/incorporação, para que a transmissão desse capital seja efetiva, não só na sua materialidade. Ou seja, não basta ter um smartphone de última geração e não saber utilizar os recursos disponíveis. O capital tecnológico objetivado compreende uma variedade de recursos como computadores desktops, notebooks, netbooks, tablets, smartphones, softwares, pagamento de serviços de telefonia móvel, acesso à internet e etc.

\footnotetext{
${ }^{3}$ Essa "mensuração" se dá com base em saberes digitais baseados na revisão e comparação das competências, habilidades e atitudes digitais identificadas como relevantes para organismos internacionais como UNESCO e OCDE. Para medição do grau de apropriação tecnológica os saberes digitais que implicam em conhecimento, uso, aplicação, frequência e intenção.
} 
E no estado institucionalizado, o capital tecnológico indica o conjunto de títulos, diplomas e certificados, que reconhecem o valor institucional dos conhecimentos e habilidades, que aqui pode ser representado pelas iniciativas certificadas da instituição para fomentar o uso de tecnologias pelos professores. Esse capital é medido em termos do número de cursos, diplomas e certificados que recebem a atribuição de um valor simbólico de reconhecimento.

Para Bourdieu (2008) os bens culturais (e aqui podemos incluir os artefatos tecnológicos) podem ser objeto de uma apropriação material, que pressupõe o capital econômico, e de uma apropriação simbólica, que pressupõe o capital cultural.

[...] para possuir máquinas, basta ter capital econômico; para se apropriar delas e utilizá-las de acordo com sua destinação específica (definida pelo capital científico e tecnológico que se encontra incorporado nelas), é preciso dispor, [...] de capital incorporado (BOURDIEU, 2008, p. 77).

Dessa forma, podemos compreender a aproximação desse conceito com o conceito de capital cultural e sua possibilidade de explicar as questões no campo educacional. Se o capital tecnológico no estado objetivado mobiliza o capital econômico, é necessário o capital tecnológico incorporado, para que o indivíduo possa usufruir de um determinado artefato tecnológico, a favor do seu capital social e também do capital escolar. Nas palavras de Ramírez Martinell, Casillas Alvarado e Méndez (2014, p. 36, tradução das autoras):

O grau de apropriação tecnológica compreende o conjunto de disposições, capacidades, habilidades, conhecimentos, conhecimentos práticos - informativos e informacionais -, tipos de uso e frequência com que as TICs são usadas nos processos educacionais.

O uso das tecnologias na educação implica uma mudança social e cultural que valoriza um novo tipo de saber e exige o conhecimento e domínio de novas habilidades intelectuais e práticas/experienciais. Acreditamos que assim como o capital cultural, o capital tecnológico é construído de acordo com as condições sociais, econômicas, escolares e culturais dos indivíduos. E a posse ou não desse capital pode dar acesso a espaços e conhecimentos que não estão disponíveis para todos, pois requer o conhecimento das regras desse campo tecnológico (BOURDIEU, 2003b).

\section{0 capital tecnológico no ensino superior}

Em sua obra "Homo Academicus", Bourdieu (2017) analisa cientificamente o campo acadêmico/universitário, onde ele mesmo estava inserido. A instituição universitária goza de uma legitimidade graças ao seu caráter racional, que é capaz de fazer a "eleição" dos "eleitos" 
e que historicamente teve suas práticas consideradas como inquestionáveis (VALLE, 2017; ZABALZA, 2007).

Valle (2017) destaca que Bourdieu fez questão de revelar conflitos, contradições, crises, desilusões, interesses, relações de força, hierarquia de prestígios, etc. da instituição universitária, que como qualquer outro campo é um campo de lutas e, marcadamente, de lutas por prestígio e distinção acadêmica, onde "[...] todos lutam contra todos, numa luta onde uns dependem dos outros" (VALLE, 2017, p. 17).

As universidades são parte do campo educativo e desenham importantes funções sociais, na medida em que são responsáveis por oferecer condições materiais e pedagógicas à formação, além de certificar os saberes e conhecimentos que os estudantes adquirem no decorrer do seu curso. Para o cumprimento dessas tarefas, as universidades contam com os professores, um grupo que se distingue, pois a eles é dada a tarefa de formar esses estudantes (RODRÍGUEZ; GARCÍA; LANDÍN, 2014). Nesse contexto, os professores universitários são detentores de uma forma institucionalizada de capital cultural " [...] que lhes assegura uma carreira burocrática e de rendimentos regulares" (BOURDIEU, 2017, p. 63).

\footnotetext{
As universidades precisam desenvolver processos que lhes permitam participar e assimilar as constantes transformações da tecnologia, mas também valorizar a posse e uso desses novos conhecimentos. Dentro das universidades, isso não visa apenas adaptar a organização às mudanças em seu ambiente, mas também como um mecanismo para garantir sua legitimidade (RODRÍGUEZ; GARCÍA; LANDÍN, 2014, p. 5-6, grifo dos autores).
}

Nesse campo de disputa por prestígio acadêmico, "na realização do seu trabalho, os professores universitários o fazem dentro de um espaço social de competência legítima, onde cada indivíduo, escola ou faculdade se esforça para obter as melhores posições" (RODRÍGUEZ; GARCÍA; LANDÍN, 2014, p. 3). Diante do exposto, acreditamos que para os fins do nosso estudo, o capital tecnológico se configura como uma importante chave de análise para compreender o nível de incorporação do uso de tecnologias digitais nas práticas pedagógicas dos professores.

\subsection{Medição de capital tecnológico de professores e estudantes}

Além da pesquisa de Ramírez Martinell, Casillas Alvarado e Méndez (2014), o estudo de Rodríguez, García e Landín (2014) nos deu subsídios para analisar o capital tecnológico dos professores. Ambos foram desenvolvidos no México e são pioneiros no que diz respeito à mensuração do nível de capital tecnológico de professores universitários e estudantes. 
A investigação de Rodríguez, García e Landín (2014) objetivou analisar o conhecimento e as habilidades digitais de professores universitários de diferentes áreas disciplinares, levando em consideração diferentes aspectos que influenciam as práticas dos professores no uso de tecnologias digitais. $\mathrm{O}$ interesse central foi explicar as diferenças que se produzem entre os professores, no que diz respeito à apropriação do capital tecnológico, relacionado ao uso, posse e validação das tecnologias digitais.

Os autores consideram que os capitais têm significado para a ação social dos indivíduos na medida em que geram e mantêm a estratificação da sociedade. Sendo assim, em cada campo específico, um determinado tipo de capital é colocado em jogo. No campo da educação, o capital que está em jogo é, sem dúvida, o capital cultural, que estabelece uma relação direta com o capital social e o capital simbólico.

A educação é um campo, cujas condições para que funcione, tal como expresso por Bourdieu, são a existência de algo em jogo e de pessoas dispostas a jogar. No contexto da pesquisa de Rodríguez, García e Landín (2014), o objeto do jogo é a implementação das tecnologias digitais "no campo profissional e acadêmico dos professores, o que implica, da mesma forma, que os agentes estejam dotados de um habitus que lhes permita conhecer e reconhecer as leis imanentes do jogo" (RODRÍGUEZ; GARCÍA; LANDÍN, 2014, p. 7). Nesse sentido, o uso de tecnologias digitais no ensino superior ultrapassa a questão tecnológica e entra no campo social e cultural, onde a posse do capital tecnológico pode ser utilizada na competição pelas posições hierárquicas.

A partir dessa análise, percebemos como os construtos teóricos desenvolvidos por Bourdieu, tais como o habitus, campo, capital cultural e capital simbólico, nos auxiliam para compreensão de como se constituem as práticas com uso de tecnologias digitais no contexto de uma instituição pública de ensino superior. Para Rodríguez, García e Landín (2014, p. 8), uma vez que os professores se apropriam dessas tecnologias, podem ser "capazes de transformá-las em elementos para melhorar seu desenvolvimento e desempenho, não apenas em suas atividades acadêmicas, mas também para a vida". Nesse sentido, o capital tecnológico compreende:

- A apropriação da cultura tecnológica, que se dá nos processos de socialização;

- Os artefatos tecnológicos e as formas de acesso a esses artefatos;

- A certificação do conhecimento. 
Novamente, esse conjunto de conhecimentos e práticas com uso de tecnologias digitais nos processos de aprendizagem configuram o capital tecnológico nas suas três formas de apresentação: incorporado, objetivado e institucionalizado.

Para identificar o capital tecnológico de estudantes e professores, Ramírez Martinell, Casillas Alvarado e Méndez (2014) elaboraram uma proposta de medição, que teve como objetivo identificar a relação do capital tecnológico com o êxito escolar. Esses indicadores compreendem uma lista de alguns "saberes digitais" importantes para pensarmos a prática pedagógica no contexto da cultura digital.

Quadro 1 - Proposta de medição do capital tecnológico

\begin{tabular}{|c|c|c|}
\hline $\begin{array}{l}\text { Expressão do Capital } \\
\text { Tecnológico }\end{array}$ & Graus de Observação & Indicadores para medição \\
\hline \multirow[t]{3}{*}{$\begin{array}{l}\text { Capital Tecnológico } \\
\text { Incorporado }\end{array}$} & $\begin{array}{l}\text { Grau de apropriação } \\
\text { tecnológica }\end{array}$ & $\begin{array}{c}\text { Manipulação de arquivos } \\
\text { Gerenciamento de dispositivos } \\
\text { Conhecimento de programas e sistemas de } \\
\text { informação } \\
\text { Criação e manipulação de conteúdo de texto } \\
\text { Criação e manipulação de dados } \\
\text { Criação e manipulação de conteúdo multimídia } \\
\text { Comunicação } \\
\text { Socialização e colaboração } \\
\text { Cidadania Digital } \\
\text { Alfabetização Digital }\end{array}$ \\
\hline & $\begin{array}{c}\text { Grau de Afinidade } \\
\text { com as Tecnologias } \\
\text { Digitais }\end{array}$ & $\begin{array}{c}\text { Percepções, atitudes e valorações sobre as } \\
\text { Tecnologias Digitais }\end{array}$ \\
\hline & $\begin{array}{l}\text { Socialização básica e } \\
\text { secundária em } \\
\text { Tecnologias Digitais }\end{array}$ & $\begin{array}{l}\text { História familiar, social e escolar } \\
\text { Tempo de inculcação } \\
\text { Grau de familiaridade }\end{array}$ \\
\hline $\begin{array}{l}\text { Capital Tecnológico } \\
\text { Objetivado }\end{array}$ & - & $\begin{array}{c}\text { Posse de equipamentos de tecnologias } \\
\text { Conectividade } \\
\text { Investimento em equipamentos e serviços de } \\
\text { Tecnologias Digitais } \\
\text { Investimento em aplicações, licenças e acessórios }\end{array}$ \\
\hline $\begin{array}{l}\text { Capital Tecnológico } \\
\text { Institucionalizado }\end{array}$ & - & $\begin{array}{l}\text { Quantidade de cursos de capacitação } \\
\text { Diplomas e certificados }\end{array}$ \\
\hline
\end{tabular}

Fonte: Ramírez Martinell, Casillas Alvarado e Méndez (2014, p. 32).Elaboração das autoras, 2018.

A hipótese inicial da pesquisa era que o nível de capital tecnológico dos professores de ensino superior estivesse relacionado com uma maior possibilidade de converter os usos sociais de tecnologia em usos pedagógicos, e que por meio do uso pedagógico, as possibilidades de encontrarmos práticas inovadoras dentro do contexto dos cursos seriam maiores.

Nas próximas seções, apresentamos os dados coletados em uma instituição federal de ensino superior, com o objetivo de encontrar, no campo empírico, os construtos teóricos que 
definiram nas pesquisas anteriores o capital tecnológico. Como mencionado acima, para o tratamento de dados foi utilizada a análise fatorial, procedimento estatístico que permite o agrupamento de fatores semelhantes ${ }^{4}$. Optamos por inverter a ordem de apresentação, começando pelo estado objetivado do capital, seguindo com o estado institucionalizado e finalizando com o capital incorporado, que representa o dado mais interessante da investigação realizada.

\subsection{O capital tecnológico objetivado}

Como vimos, o estado objetivado do capital tecnológico compreende o conjunto de objetos tecnológicos que são apropriados em sua materialidade e em seu significado simbólico, tais como dispositivos tecnológicos, conectividade com a internet, licenças de software, serviços de tecnologia em geral que impliquem em investimento financeiro. Nessa pesquisa, o capital tecnológico objetivado foi medido com base nas questões que indicavam posse de artefatos tecnológicos (computador de mesa, televisão, computador portátil, tablet), celular com acesso à internet, conhecimento do sistema operacional do celular.

Os resultados da análise fatorial resultaram em um único fator, o que indica que as variáveis analisadas poderiam ser sintetizadas em apenas uma dimensão, mas as estatísticas de confiabilidade não apresentaram resultados significativos. Tal resultado pode ter sido influenciado pelo baixo número de respostas obtidas com o questionário dos professores (59 respostas) e, principalmente, pela pouca variabilidade de respostas para as questões: indicador se possui celular com acesso à internet; indicador se conhece o sistema operacional do celular.

Mesmo não gerando estatísticas confiáveis para a análise estatística, a análise descritiva dos dados do questionário indica os tipos de recursos tecnológicos que os professores possuem. O celular com acesso à internet (smartphone) está presente na vida de 95\% dos professores, seguido do notebook, em que $94 \%$ dos professores informaram possuir. O tablet também aparece de forma considerável (49\% dos professores) e o computador de mesa quase na mesma proporção.

Considerando que os professores possuem notebooks, celular com acesso à internet $\mathrm{e}$ acesso livre à internet no espaço institucional (a maioria dos cursos investigados têm acesso

\footnotetext{
${ }^{4} \mathrm{~A}$ análise fatorial é um procedimento estatístico que tem como objetivo descrever a variabilidade original de certo vetor X em um número menor de novas variáveis, chamadas de fatores, que não são correlacionados entre si, por meio de um modelo linear. Cada variável X é padronizada, subtraindo à média e dividindo pelo desvio padrão, sendo transformada em uma nova variável Z, que tem média 0 e variância 1. (FILHO; SILVA JÚNIOR, 2010). Nesse modelo, parte da variabilidade original do vetor X está atribuída aos fatores que estão incluídos no modelo, chamada de "comunalidade". O restante da variabilidade está atribuído aos fatores que não foram incluídas no modelo, ou seja, o erro. Essa variabilidade é chamada de "variância específica". Como as variáveis originais estão padronizadas, a soma da "comunalidade" e da "variância específica" é 1 . Em linhas gerais, o que se espera é que as variáveis padronizadas $\mathrm{Zi}, \mathrm{i}=1,2, \mathrm{p}$ (último elemento) estejam agrupadas em subconjuntos de novas variáveis mutuamente não correlacionadas, sendo que a análise fatorial teria como objetivo o encontro destes fatores de
} agrupamento. 
também na sala de aula), poderíamos esperar que o uso social, mas principalmente pedagógico de tecnologias fosse bastante intenso. Porém, assim como o capital cultural objetivado - posse de bens materiais - não significa apropriação e uso, resulta evidente que o mesmo acontece com o capital tecnológico. Como ainda não há uma cultura institucional que promova ações que estimulem o uso pedagógico de tecnologias digitais entre estudantes e professores, a posse dos artefatos tecnológicos pouco pode dizer sobre as práticas de uso efetivas. No entanto, esse dado indica que há um potencial de uso, que pode ser explorado pela instituição, para promover ações em benefício dos cursos de formação de professores.

\subsection{O capital tecnológico institucionalizado}

Na mesma lógica do capital cultural institucionalizado (BOURDIEU, 2007), o capital tecnológico institucionalizado seria uma "certidão de competência" e habilidades para uso de tecnologias, agregada por meio de cursos de formação continuada para uso de tecnologias digitais na prática pedagógica. Na instituição investigada, os cursos de formação continuada acontecem desde 2014, mas apenas em 2016 os certificados desses cursos passaram a ter um reconhecimento institucional garantido em resolução, que pontua para o professor na sua avaliação anual de progressão funcional no Sistema de Avaliação Docente ${ }^{5}$.

Para compor o índice de capital tecnológico institucionalizado dos professores, a análise fatorial resultou de dois fatores/dimensões: (1) participação em curso sobre tecnologia ou informática de modo geral durante a graduação ou pós-graduação; (2) participação em curso de formação em tecnologias oferecido pela instituição. Também neste caso as medidas de confiabilidade e ajuste não se mostram estatisticamente significativas.

No caso dos professores, $69,5 \%$ indicaram ter realizado algum curso sobre tecnologia ou informática de modo geral, depois de sua entrada na instituição. Dentre esses professores que realizaram os cursos, a maioria o fez para capacitação para docência na educação a distância, principalmente para uso do Ambiente Virtual de Aprendizagem (plataforma Moodle). Os demais indicaram cursos de informática básica, tais como editores de texto. Dos professores respondentes, 71,2\% não participaram de nenhum dos cursos oferecidos pela instituição, e desses, $47,6 \%$ afirmaram não ter participado por desconhecimento da oferta dos cursos.

\footnotetext{
${ }^{5}$ Uma resolução publicada em março de 2018 regulamenta, no âmbito instituição, os critérios e os procedimentos de avaliação de desempenho docente, progressão e promoção funcionais, aceleração da promoção, reposicionamento por titulação, bem como Retribuição por Titulação (RT) na Carreira de Magistério Superior A resolução prevê cinco pontos por participação em cursos de formação continuada para docência no ensino superior.
} 


\subsection{O capital tecnológico incorporado}

O capital tecnológico incorporado, como dito acima, pressupõe uma incorporação e um trabalho de inculcação e assimilação que deve custar tempo de investimento. O tempo de acúmulo do capital tecnológico incorporado "engloba a totalidade do tempo de socialização" (BOURDIEU, 2007, p. 76). É ele que impulsiona a ação, as escolhas, o habitus de cada agente, de acordo com o campo em que está inserido e de acordo com as suas condições reais de existência nesse campo.

O grau de apropriação tecnológica compreende o conjunto de disposições, capacidades, habilidades, conhecimentos, conhecimentos práticos - informativos e informacionais -, tipos de uso e frequência com que as tecnologias digitais são usadas nos processos educacionais (RAMÍREZ MARTINELL; CASILLAS ALVARADO; MÉNDEZ, 2014). No contexto dessa pesquisa, a composição do índice de capital tecnológico incorporado dos professores foi realizada por análise fatorial. As tabelas a seguir indicam a composição desses índices e mostram o critério de Kaiser-Meyer-Olkin (KMO), uma medida utilizada para quantificar o grau de intercorrelações entre as variáveis ${ }^{6}$.

Tabela 1 - KMO and Bartlett's Test (Capital Tecnológico Incorporado dos professores)

\begin{tabular}{l|l|r}
\hline \multicolumn{2}{l|}{ Kaiser-Meyer-Olkin Measure of Sampling Adequacy } & $\mathbf{0 , 7 9 5}$ \\
\hline Bartlett's Test of Sphericity & Approx. Chi-Square & 169,985 \\
\cline { 2 - 3 } & Df & 28 \\
\cline { 2 - 3 } & Sig. & 000 \\
\hline
\end{tabular}

Fonte: Oliveira, 2018.

Tabela 2 - Estatísticas de Confiabilidade (Capital Tecnológico Incorporado dos professores)

\begin{tabular}{rr|r}
\hline Cronbach's Alpha & N de itens \\
\hline, 783 & \\
\hline
\end{tabular}

Fonte: Oliveira, 2018.

O processo de análise fatorial resultou em dois fatores/dimensões no indicador de capital tecnológico incorporado. A dimensão 1 - que poderíamos definir de uso pedagógico de tecnologias para preparação da aula e atividades em sala - é composta por 5 variáveis: (i) média de horas por dia de uso do computador; (ii) frequência com que utiliza recursos digitais para desenvolver atividades em sala de aula com os estudantes; (iii) frequência com que os estudantes, orientados pelo professor, usam computador, tablet ou celular para atividades; (iv) frequência com que utiliza ferramentas tecnológicas na sala de aula; (v) frequência com que

${ }^{6} \mathrm{O}$ valor do KMO varia entre 0 e 1 , de maneira que os valores menores que 0,5 são considerados inaceitáveis; valores entre 0,5 e 0,7 são considerados medíocres; valores entre 0,7 e 0,8 são considerados bons; valores maiores que 0,8 e 0,9 são considerados ótimos e excelentes, respectivamente (DAMASIO, 2012). 
utiliza estratégias didáticas nas aulas. Já a dimensão 2 - que podemos categorizar como uso de tecnologias para comunicação e compartilhamento - é formada por três variáveis: (i) utilização de recursos digitais para se comunicar com os colegas de trabalho; (ii) frequência com que utiliza recursos digitais para se comunicar com os estudantes; (iii) frequência com que utiliza recursos digitais para compartilhar material das aulas com os estudantes.

O índice de capital tecnológico incorporado dos professores foi de 0,795 e merece destaque, pois está bem perto do que é considerado excelente, de acordo com o critério de Kaiser-Meyer-Olkin (KMO). Nesse sentido, os dados indicam que os professores que possuem um alto índice de uso pedagógico de tecnologias digitais (18 professores da amostra, de um total de 59 respondentes) mostram indícios de incorporação desses usos em suas práticas pedagógicas. São indícios, pois essa medição é global, de forma que não foi possível, com a estrutura dos questionários, criar uma escala para medir o capital tecnológico incorporado em 3 ou mais níveis, ou seja, para saber o grau de incorporação das tecnologias digitais nas práticas pedagógicas.

Em colaboração com a análise do capital tecnológico incorporado, o gráfico a seguir foi construído com base numa questão que pedia aos professores a indicação do que eles conseguiam fazer sem nenhuma dificuldade. Das 17 habilidades listadas, em 8 habilidades mais de $60 \%$ dos professores indicaram não ter nenhuma dificuldade em executar as ações.

Gráfico 1 - Habilidades dos professores para uso de tecnologias digitais

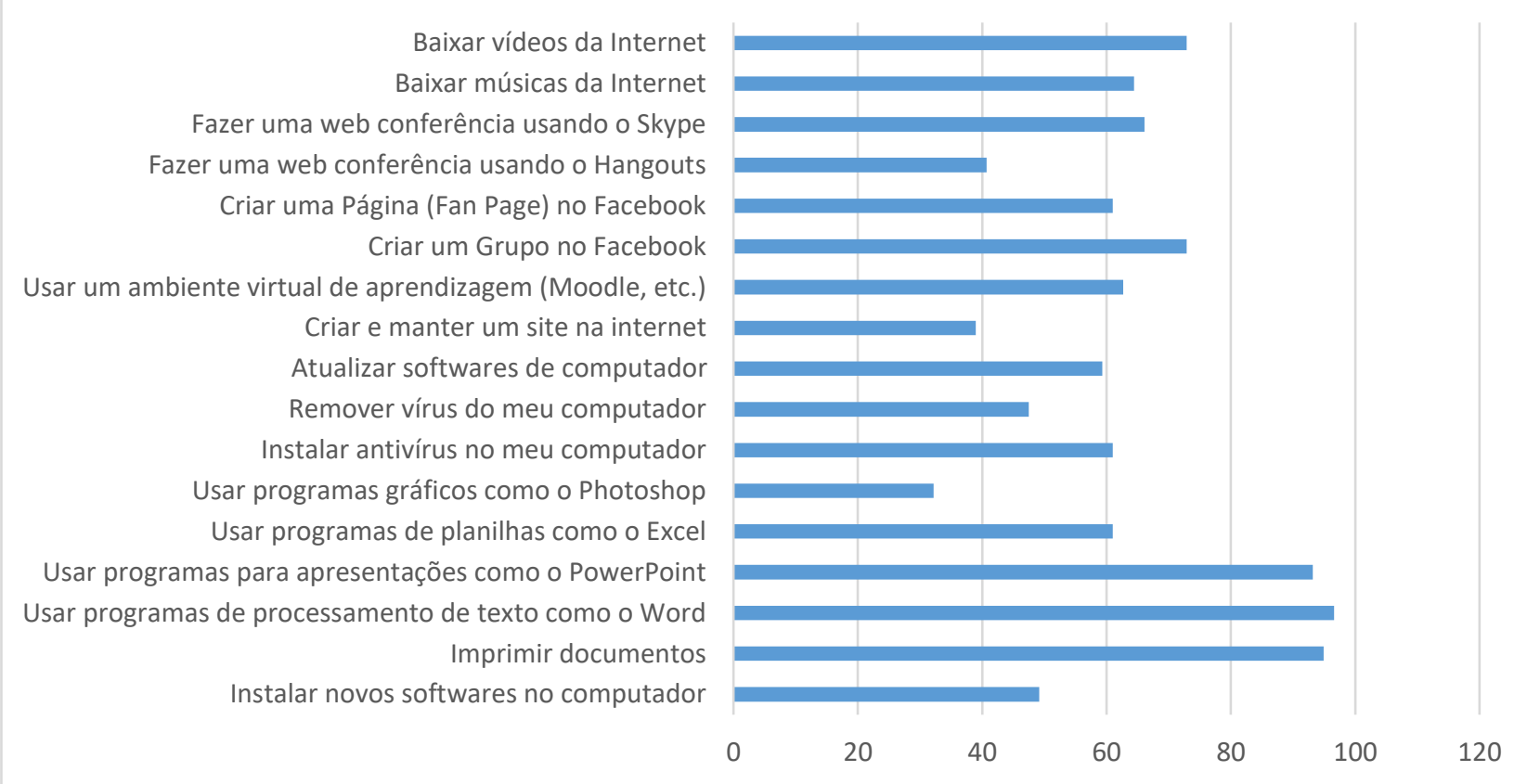

Fonte: Elaboração das autoras, 2018. 
As habilidades para o uso de tecnologias são fatores que corroboram para o entendimento das práticas incorporadas, que, paralelamente ao índice, podem nos ajudar a entender a correlação das habilidades instrumentais para as práticas pedagógicas, ou seja, da conversão do uso social para o uso pedagógico de tecnologias digitais.

\section{Reflexões sobre a relação do capital tecnológico incorporado com as práticas pedagógicas inovadoras}

A pesquisa investigou a relação entre o nível de capital tecnológico dos professores, os usos pedagógicos de tecnologias e as práticas inovadoras. Na construção dos questionários, não estabelecemos, a priori, o que consideramos como práticas inovadoras, justamente por entender que elas dependem de vários fatores, tais como: projeto do curso, infraestrutura física e tecnológica do curso, formação do professor e outras particularidades do contexto específico do curso, o que não nos permite generalizar nenhum tipo de ação, que pode ser inovadora num contexto e no outro não.

A tabela a seguir apresenta um comparativo entre o índice de uso social e uso pedagógico de tecnologias digitais ${ }^{7}$. Ela mostra que um número muito baixo (4 casos) de professores apresentou alto uso social e alto uso pedagógico de tecnologias digitais. E do total dos casos, incluindo os professores que apresentam baixo uso social (14 casos), apenas 30,5\% dos professores fazem uso pedagógico de tecnologias digitais.

Tabela 3 - Comparativo entre uso social e uso pedagógico de tecnologias digitais pelos professores

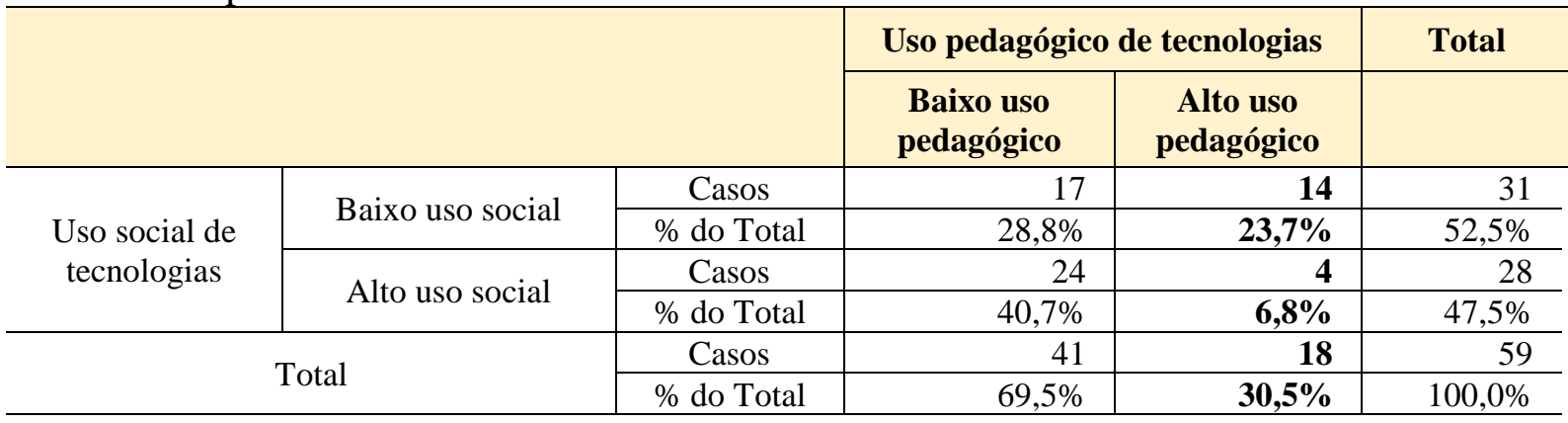

Fonte: Elaboração das autoras, 2018.

Diante desse cenário, consideramos que as práticas inovadoras podem ser aquelas que se vinculam às ações que os alunos e professores consideraram como inovadoras. Com esse filtro, comparamos o que os estudantes e professores registraram como práticas inovadoras com

${ }^{7}$ Essa tabela é bivariada, ou seja, baseada nas duas variáveis principais: uso social de tecnologias digitais e uso pedagógico de tecnologias digitais. 
as ações que os professores nas entrevistas afirmaram desenvolver com uso de tecnologias digitais na prática pedagógica.

Para melhor identificar as práticas incorporadas e destacar aquelas que podem ser consideradas inovadoras no contexto, a fonte principal de análise foram as entrevistas. Entre os vinte e quatro professores entrevistados, apenas dois informaram trabalhar com o Facebook e um mencionou uma atividade de produção de vídeo com o celular. Outras atividades com vídeo foram mencionadas, mas não envolviam produção.

Nesse contexto, podemos destacar duas professoras (Professora 1/Câmpus A e Professora 1/Câmpus D) que desenvolvem atividades que podem ser consideradas inovadoras no contexto do curso, que fogem ao trivial do uso de tecnologias que a grande maioria dos professores fazem: data show, slides, grupos de WhatsApp e mostras de vídeos.

As professoras em destaque tiveram uma trajetória de trabalho com as tecnologias digitais. São relativamente novas na instituição, e ambas têm "remado contra a maré", pois estão à mercê de projetos pedagógicos engessados e inseridas em um grupo de professores que não se percebe responsável por essa formação. O quadro a seguir mostra o perfil construído com base nas entrevistas.

Quadro 2 - Perfil das professoras

\begin{tabular}{|c|c|c|}
\hline & Professora 1/Câmpus A & Professora 1/Câmpus D \\
\hline Tempo de instituição & 8 anos. & 8 anos. \\
\hline Formação & $\begin{array}{l}\text { História; } \\
\text { Processamento de dados. }\end{array}$ & Pedagogia. \\
\hline Pós-graduação & Educação. & $\begin{array}{l}\text { Educação com foco nas tecnologias } \\
\text { digitais. }\end{array}$ \\
\hline Trajetória de trabalho & $\begin{array}{l}\text { Educação Básica. } \\
\text { Museu da Imagem e do Som. }\end{array}$ & Educação Básica. \\
\hline $\begin{array}{l}\text { Experiências com as } \\
\text { tecnologias digitais }\end{array}$ & $\begin{array}{l}\text { Intercâmbio de alunos de outros } \\
\text { países por e-mail; } \\
\text { Exposição fotográfica e de vídeos } \\
\text { produzidos pelos alunos; } \\
\text { Educação a Distância. }\end{array}$ & $\begin{array}{l}\text { Iniciou o trabalho da sala de } \\
\text { tecnologia; } \\
\text { Cursos de Extensão para formar } \\
\text { professores no uso das tecnologias; } \\
\text { Educação a Distância. }\end{array}$ \\
\hline
\end{tabular}

Fonte: Elaboração das autoras, 2018.

A Professora 1 do Câmpus D conta que a área do seu concurso era Didática e Tecnologia Educacional e que ao assumir o cargo para ministrar aulas no curso de Pedagogia foi recebida com a seguinte expressão: "Você fez um concurso para uma área que não existe". Quando ela entrou não havia nenhuma disciplina relacionada às tecnologias no currículo do curso e isso a motivou a oferecer um curso de extensão, duas vezes ao ano, pois a adesão pelos alunos era 
grande. E depois de um tempo, ela conseguiu a alteração da disciplina que de optativa se tornou obrigatória.

\begin{abstract}
Recentemente, eu tenho usado os grupos do Facebook para várias atividades. Para o projeto de extensão que tenho, para as orientações de TCC e para as disciplinas que ministro. Então, cada disciplina nesses cursos, acho que tem uns 10 grupos ali que eu tenho. Alguns eu arquivo e outros continuo e só vou mudando o nome da disciplina. E assim, uma coisa também que tem dado certo, eles usam muito o Messenger, pois encaminham as mensagens, dúvidas e tal. E aí quando eu posso, eu respondo. Então, sai um pouco assim, só na sala de aula. E agora tem o Wi-Fi aqui na universidade então eles podem. Inclusive, até nas minhas aulas eu os deixo usarem os textos, quem não imprimiu por várias razões, então eles abrem o arquivo e acompanham as aulas pelo notebook. Notebook, alguns têm, poucos têm. A maior parte é celular mesmo (Professora 1/Câmpus D).
\end{abstract}

A professora ressalta que desenvolve essas ações apenas com a ajuda dos alunos e com as parcerias que faz com o Núcleo de Tecnologia Educacional (NTE) da Secretaria Estadual de Educação (SED/MS), pois não tem outro professor no curso ou no Câmpus que se interesse pela temática. Ela sinaliza ainda que essas ações na instituição são bem isoladas, "Porque cada um tem a sua área, cada um cuida da sua área" (Professora 1/Câmpus D).

Em seu último curso de extensão, ela trabalhou com aplicativos para dispositivos móveis no ensino fundamental. E os alunos do curso de Pedagogia participaram desse processo, vivenciando de perto como a tecnologia pode ser utilizada proficuamente para os processos de construção de aprendizagem na escola. A Professora também atua na Educação a Distância, onde tem ministrado aulas num curso de pós-graduação na área de Mídias na Educação.

A Professora 1 do Câmpus A tem uma trajetória de trabalho com as tecnologias digitais iniciada em 1997, quando desenvolvia projetos nas escolas de educação básica, depois de ter passado por uma experiência de trabalho no Museu da Imagem e do Som em São Paulo no início da década de 90, quando o acesso aos computadores ainda era bem restrito a algumas instituições. Já no curso de Pedagogia, ela começou a desenvolver um trabalho de captação de imagens, edição de imagens e de vídeos, que resultou em exposições fotográficas e mostra de vídeos produzidos no âmbito da disciplina de Metodologia do Ensino de História. No curso de Pedagogia, ela ofereceu uma disciplina optativa de Educação, Mídias e Tecnologias, e desenvolveu um Blog, que tem sido alimentado com as produções dos alunos a cada nova oferta da disciplina. 
Então, eu gosto bastante de [...] propor atividades de investigação em sala de aula, trabalho muito com o celular na sala de aula, gosto muito de trabalhar com celular na sala de aula. Os alunos, eu peço para eles acessarem, em Políticas Educacionais e quando tenho dúvida de uma informação, peço para eles buscarem e confirmarem. Eles me fazem uma pergunta, eu peço para eles buscarem o dado e trazerem para debate. Às vezes, eu trago um documento, alguma provocação, peço para eles procurarem na internet a partir do celular deles. Eu também utilizo muito o celular e também mando por e-mail para eles os materiais da aula, e eles abrem na sala de aula textos no celular. Alguns, muitos deles trazem o notebook, porque eu autorizo o uso do notebook na sala de aula, e eles podem abrir os notebooks, com os textos e fazer informações também durante a aula, então isso também é tranquilo (Professora 1/Câmpus A).

A professora também trabalha no curso de Pedagogia a distância e tem buscado fazer a interlocução dessas práticas entre ambos os cursos, embora ainda não tenha conseguido utilizar o Moodle como apoio ao presencial, por não ter tido tempo de preparar o ambiente virtual. Assim como a Professora do Câmpus D, destaca que também trabalha sozinha, sem apoio efetivo dos colegas de curso, mas sempre busca novas estratégias para o trabalho didático com os alunos, aprendendo em conjunto com eles.

Esses dois perfis demonstram o peso que tem o capital tecnológico incorporado na produção de práticas inovadoras mesmo em contextos que não são favoráveis à inovação. Em ambos os casos, podemos destacar alguns elementos desfavoráveis: a) o projeto pedagógico de curso não apresenta uma concepção metodológica para o trabalho com as tecnologias digitais; b) o grupo de professores considera que esse trabalho deve ser feito por alguém "da área"; c) as ações são isoladas do contexto do curso; d) a infraestrutura tecnológica é precária.

O capital tecnológico incorporado, que é medido pelo uso social e pelo uso pedagógico de tecnologias digitais, nos remete à história e trajetória de cada uma das professoras, pois essa prática é resultado de vivências e experiências, que somadas à formação e às habilidades que as professoras apresentam em cada contexto, podem constituir práticas pedagógicas inovadoras.

\section{Considerações finais}

No contexto da cultura digital, a pesquisa nos permitiu distinguir o capital tecnológico como um elemento que pode contribuir para a construção de práticas pedagógicas inovadoras. Para Bourdieu (2003a, p. 57), "qualquer que seja o campo, ele é objeto de luta tanto em sua representação quanto em sua realidade”. O campo acadêmico/universitário é um espaço de disputas que não são veladas, pois estão explícitas. As regras do jogo nesse campo estão postas nas normativas institucionais, nas práticas enraizadas dentro dos cursos, nos discursos daqueles que estão há mais tempo na instituição, nos grupos de pesquisa, nas associações de pesquisa e pós-graduação, no Currículo Lattes, etc. 
Os que entram em campo para jogar já entram conhecendo boa parte das regras, pois para entrar é necessário encarar um processo seletivo que tem como objetivo escolher aqueles que têm um potencial de competir e se manter nesse jogo da vida acadêmica. Nesse sentido, o domínio da tecnologia é algo que pode dar ao professor uma distinção dentro do curso não só perante os colegas, mas principalmente perante os alunos, que apresentam um uso pedagógico mais elevado e que esperam dos professores uma prática diferenciada com uso de tecnologias.

Nesse campo, é o nível de capital tecnológico que vai dar ao professor as chances de "competir", ou seja, de desenvolver práticas que tenham potencial de inovação e oportunizem aos alunos experiências de aprendizagem com uso de tecnologias digitais, que possam também constituir exemplos para sua futura prática docente.

Se o habitus é uma estrutura incorporada no processo de socialização e formação, cujas disposições influenciam as práticas dos professores no contexto em que estão inseridos, podemos entender que as práticas inovadoras podem ser individualizadas e esparsas, como percebemos na pesquisa, pois ainda não existe nesse contexto uma cultura para o uso de tecnologias digitais que permita constituir um habitus de grupo.

Considerando que as regras do campo corroboram para constituir as práticas estruturadas no interior do campo e diante das limitações do contexto institucional, os professores tendem a desenvolver práticas mais tradicionais, que se distanciam da realidade cultural dos alunos, não porque não as consideram importantes, mas porque a estrutura de base de sua socialização, trajetórias e experiências não são fortes o bastante para conseguir romper com a lógica do campo.

\section{Referências}

BOURDIEU, Pierre. Coisas ditas. Tradução de Cássia R. da Silveira e Denise Moreno Pegorim. São Paulo: Brasiliense, 2004.

BOURDIEU, Pierre. Esboço de uma teoria da prática. In: ORTIZ, Renato. (Org.). A sociologia de Pierre Bourdieu. São Paulo: Olho D’Água, 2003b.

BOURDIEU, Pierre. Homo academicus. Tradução de Ione Ribeiro Valle e Nilton Valle. 2. ed. Florianópolis: UFSC, 2017.

BOURDIEU, Pierre. O campo científico. In: ORTIZ, Renato. (Org.). A sociologia de Pierre Bourdieu. São Paulo: Olho D’Água, 2003a.

BOURDIEU, Pierre. Os três estados do capital cultural. In: NOGUEIRA, Maria Alice; CATTANI, A. (Org.). Escritos de educação. Petrópolis: Vozes, 2007. 
BOURDIEU, Pierre. Razões práticas: sobre a teoria da ação. 9. ed. Tradução de Mariza Corrêa. Campinas: Papirus, 2008.

CASTELLS, Manuel. A sociedade em rede: do conhecimento à política. In: CASTELLS, Manuel; CARDOSO, Gustavo. (Org.). A sociedade em rede: do conhecimento à acção política. Imprensa Nacional/Casa da Moeda, 2005.

DAMÁSIO, Bruno Figueiredo. Uso da análise fatorial exploratória em psicologia. Avaliação Psicológica, Campinas, v. 11, n. 2, 2012. Disponível em: https://bit.ly/2JUWgfo. Acesso em: 08 mar. 2021.

FILHO, Dalson Brito Figueiredo; SILVA JÚNIOR, José Alexandre da. Visão além do alcance: uma introdução à análise fatorial. Opinião Pública, Campinas, v. 16, n. 1, jun. 2010. Disponível em: https://bit.ly/2M8mTxx . Acesso em: 08 mar. 2021.

FREITAS, Christiana Soares de. O capital tecnológico-informacional. Estudos de Sociologia, Araraquara, v. 9, n. 17, 2004. Disponível em: https://bit.ly/3fvowFV. Acesso em: 19 maio. 2021.

LARAIA, Roque de Barros. Cultura: um conceito antropológico. 22. ed. Rio de Janeiro: Zahar, 2008.

MINGOTI, Sueli. Análise de dados através de métodos de estatística multivariada. Uma abordagem aplicada. Belo Horizonte: UFMG, 2013.

OLIVEIRA, André Luiz Regis de. Relatório final: análises estatísticas dos questionários de professores e alunos. 2018.

RAMÍREZ MARTINELL, Alberto; CASILLAS ALVARADO, Miguel Angel; MÉNDEZ, Verónica Ortiz. El capital tecnológico una nueva especie del capital cultural. Una propuesta para su medición. In: RAMÍREZ MARTINELL, Alberto; CASILLAS ALVARADO, Miguel Angel. (Org.). Háblame de TIC: Tecnología Digital en la Educación Superior. Córdoba: Brujas, 2014. Disponível em: https://bit.ly/3uZxrpI. Acesso em: 14 abr. 2021.

RODRÍGUEZ, Lilián Ivetthe Salado; GARCÍA, Mario Alberto Velázquez; LANDÍN, Reyna Isabel Ochoa. El capital tecnológico y el ejercicio docente: el caso de la Universidad Estatal de Sonora. In: Congreso Iberoamericano de Ciencia, Tecnología, Innovación y Educación. Anais eletrônicos... Buenos Aires, 2014. Disponível em: https://bit.ly/3ovA6VE. Acesso em: 18 jan. 2021.

SILVA, Marco. Indicadores de interatividade para o professor presencial e on-line. Revista Diálogo Educacional, Paraná, v. 4, n. 12, maio./ago. 2004. Disponível em: https://bit.ly/2nwu7Bg. Acesso em: 15 maio. 2021.

VALLE, Ione Ribeiro. Apresentação: ler homo academicus. In: BOURDIEU, Pierre. Homo academicus. Tradução de Ione Ribeiro Valle e Nilton Valle. 2. ed. Florianópolis: UFSC, 2017.

ZABALZA, Miguel A. O ensino universitário: seu cenário e protagonistas. Tradução Ernani Rosa. São Paulo: Artmed, 2007. 